\title{
Hemostatic Function in Young Subjects With Central Obesity: Relationship With Left Ventricular Function
}

\author{
Giuseppe Licata, Rosario Scaglione, Gino Avellone, Attilio Ganguzza, Salvatore Corrao, \\ Sabrina Arnone, and Tiziana Di Chiara
}

\begin{abstract}
This study was designed to evaluate coagulation and fibrinolysis activity and their relationship with left ventricular function in young obese subjects with central fat distribution. We assessed coagulation and fibrinolysis activity by evaluation of factor VII activity, fibrinogen and plasminogen, plasminogen activator inhibitor (PAI), and tissue plasminogen activator antigen basally (tPA1) and after venous occlusion (tPA2). These measures were evaluated in young ( $<40$ years) obese subjects with central fat distribution ( $n=19$ ) and in comparable lean subjects $(n=20)$. Blood glucose, triglycerides, total and high-density lipoprotein (HDL) cholesterol, apolipoprotein (apo) A1 and apo B, fasting immunoreactive insulin, and lipoprotein(a) levels were also measured by current methods. Left ventricular ejection fraction (LVEF) and peak filling rate (PFR) determined by radionuclide angiocardiography and left ventricular mass (LVM) and LVM indexed for body height (LVM/H) determined by echocardiographic study were calculated. Central obesity was evaluated by the waist to hip ratio (WHR) according to the criteria of the Italian Consensus Conference of Obesity. Factor VII $(P<.001)$, fibrinogen $(P<.001)$, plasminogen $(P<.001)$, PAI activity $(P<.001)$, tPA1 $(P<.02)$, fasting blood glucose $(P<.01)$, apo $B(P<.02)$, and immunoreactive insulin $(P<.01)$ were significantly higher in obese than in lean subjects. In contrast, HDL cholesterol $(P<.01), \mathrm{tPA}(P<.01), \mathrm{LVEF}(P<.001)$, and PFR $(P<.02)$ were significantly lower in obese than in lean subjects. In all subjects, WHR correlated directly with fibrinogen and inversely with TPA2; LVEF correlated inversely with tPA1, PAl, and fibrinogen; and PFR correlated inversely with factor VII activity. Multiple regression analysis indicated that WHR and PAI were independent predictors of LVEF. These results indicate that obese subjects with central fat distribution are characterized by a hypercoagulable state associated with a silent left ventricular dysfunction. Such alterations might be responsible for the higher cardiovascular risk in subjects with central obesity.
\end{abstract}

Copyright $\odot 1995$ by W.B. Saunders Company

O BESITY is an important risk factor for cardiovascular disease, especially when there is a central fat distribution. Several indications suggest an independent role of obesity in promoting cardiovascular disease; however, this has not been universally accepted. ${ }^{1}$ In addition, recent follow-up results of the Harvard Growth Study indicate that the risk of morbidity from coronary heart disease and atherosclerosis increased among men and women who had been overweight in adolescence. ${ }^{2}$ The effects of obesity in adolescence on adult mortality have been demonstrated to reflect the central deposition of fat that occurs in adolescence. 3,4

On the other hand, alterations in hemostatic function are emerging predictors of coronary heart disease or cardiac events. In fact, some epidemiological data indicate that activated coagulation and impaired fibrinolytic function might be associated with an increased risk of dying of cardiovascular disease. ${ }^{5-8}$ In some of these studies, coagulation or fibrinolysis activity was also related to body mass index (BMI) or waist to hip ratio (WHR) ${ }^{6,8}$

These data might suggest an early connection between obesity and atherosclerosis and its clinical manifestations. Our previous data indicated a depressed ejection fraction at rest and after exercise in young normotensive obese subjects without major risk factors for cardiovascular disease. ${ }^{9,10}$ In the same subjects, a decrease in $\beta$-adrenergic receptor density and an impaired diastolic function were found. ${ }^{11,12}$

Nevertheless, few data are available on the relationship between obesity, hemostatic activity, and left ventricular function. ${ }^{8,13-15}$

In the present study, coagulation and fibrinolysis function have been evaluated in young normotensive obese subjects with central fat distribution and without major risk factors for cardiovascular disease or events, ie, smoking, hypertension, diabetes, and lipid abnormalities. Our final goal was to recognize relationships among body fat distribution, hemostatic measurements, and left ventricular function in obese subjects with central fat distribution.

\section{SUBJECTS AND METHODS}

\section{Subjects}

A total of 39 subjects, 19 obese and 20 lean healthy controls, younger than 40 years were included in this study. Obese subjects were recruited from individuals attending the obesity center of the Internal Medicine Department at the University of Palermo. Lean controls were chosen from a group of subjects undergoing a clinical evaluation and found to be healthy. Subjects were considered obese according to BMI values proposed by the Italian Consensus Conference on Obesity. ${ }^{16}$ Cutoff values for obesity were a BMI of at least $30.5 \mathrm{~kg} / \mathrm{m}^{2}$ for men and $27.3 \mathrm{~kg} / \mathrm{m}^{2}$ for women. Lean subjects were selected on the basis of BMI values of less than 24.7 $\mathrm{kg} / \mathrm{m}^{2}$ for women and $25 \mathrm{~kg} / \mathrm{m}^{2}$ for men. Each subject's fat distribution was assessed by measuring WHR in the standing position as previously reported. ${ }^{9,10,12}$ Central fat distribution was defined on the basis of the sex-specific 85 th percentile of WHR values. ${ }^{16}$ In view of this, the cutoff value for central obesity was considered at least 0.81 for women and 0.92 for men. According to

From the Department of Internal Medicine, University of Palermo, Palermo, Italy.

Submitted August 1, 1994; accepted March 9, 1995.

Supported in part by Grant No. 93.00581.PF41 from the National Research Council (CNR)-Targeted Project "Prevention and Control Disease Factors"; Subproject SP8 "Control Cardiovascular Pathology."

Address reprint requests to Rosanio Scaglione, $M D$, Via Lombardia n.9, 90144 Palermo, Italy.

Copyright 1995 by W.B. Saunders Company

0026-0495/95/4411-0009\$03.0010 
these criteria, obese subjects with peripheral fat distribution (WHR $<0.81$ for women and $<0.92$ for men) were excluded. Following this procedure, subjects were subdivided into two groups: group 1 (lean subjects), 10 men and 10 women aged 24 to 39 years (mean, $34 \pm 5$ ) with a BMI mean value of $23.3 \pm 0.8$ and a WHR mean value of $0.75 \pm 0.04$; and group 2 (obese subjects with central fat distribution), nine men and 10 women aged 28 to 38 years (mean, $33 \pm 4$ ) with a BMI mean value of $36.3 \pm 4.7$ and a WHR mean value of $0.93 \pm 0.06$.

All subjects were normotensive (systolic blood pressure consistently $<140 \mathrm{~mm} \mathrm{Hg}$ and diastolic blood pressure $<90 \mathrm{~mm} \mathrm{Hg}$ ) and matched as closely as possible with regard to age, gender, and height (Table 1). Arterial blood pressure was measured with an appropriately large cuff in obese subjects. ${ }^{1,9,10,12}$

Exclusion criteria included smoking habits, insulin-dependent or -independent diabetes mellitus, hyperlipoproteinemia (total cholesterol $>220 \mathrm{mg} / \mathrm{dL}$ ), endocrine and cardiovascular disease, hypertension, electrolyte imbalance, alcoholism, drug addiction, and psychiatric problems.

All obese subjects had been left untreated for at least 2 weeks before the study. During this withdrawal period, no significant changes in body weight were observed. This study was approved by the Ethics Committee of our Institute, and each patient gave informed consent after a detailed description of the study procedure.

Preliminary investigations included determination of blood and urinary electrolytes, creatinine clearance, blood glucose, oral glucose tolerance, total serum cholesterol, high-density lipoprotein (HDL) cholesterol, and triglycerides. Creatinine clearance, serum and urinary electrolytes, and the oral glucose tolerance test were used to exclude subjects with renal impairment, electrolyte imbalance, and diabetes mellitus, respectively. These measurements did not differ significantly between lean and obese subjects.

\section{Laboratory Methods}

Venous blood samples were drawn after an overnight fast using a $1.2-\mathrm{mm}$ siliconized needle without or with minimal stasis. We determined the following in serum using conventional enzymatic methods (Boehringer Mannheim, Milano, Italy): blood glucose (Glucose Oxidase), triglycerides (Glycerol Phosphate Oxidase),

Table 1. Characteristics of Lean and Obese Subjects

\begin{tabular}{lcc}
\hline \multicolumn{1}{c}{ Characteristic } & Lean $(\mathrm{n}=20)$ & Obese $(\mathrm{n}=19)$ \\
\hline Gender $(\mathrm{M} / \mathrm{F})$ & $10 / 10$ & $9 / 10$ \\
Age $(\mathrm{yr})$ & $34 \pm 5$ & $33 \pm 4$ \\
Height $(\mathrm{cm})$ & $165 \pm 8.3$ & $163 \pm 8.5$ \\
BMl $\left(\mathrm{kg} / \mathrm{m}^{2}\right)$ & $23.3 \pm 0.8$ & $36.3 \pm 4.7^{*}$ \\
WHR & $0.75 \pm 0.04$ & $0.93 \pm 0.06^{*}$ \\
FBG $(\mathrm{mg} / \mathrm{dL})$ & $89 \pm 4$ & $93 \pm 4.5 \dagger$ \\
Cholesterol $(\mathrm{mg} / \mathrm{dL})$ & $176 \pm 18$ & $193 \pm 24$ \\
HDL cholesterol & $47.3 \pm 3$ & $41 \pm 6 \dagger$ \\
TG $(\mathrm{mg} / \mathrm{dL})$ & $120 \pm 21$ & $133 \pm 42$ \\
Lp $(\mathrm{a})(\mathrm{mg} / \mathrm{dL})$ & $10.3 \pm 5.4$ & $18 \pm 7 \dagger$ \\
Apo A1 $(\mathrm{mg} / \mathrm{dL})$ & $150 \pm 12$ & $153 \pm 24$ \\
Apo B $(\mathrm{mg} / \mathrm{dL})$ & $105 \pm 15$ & $146 \pm 68 \ddagger$ \\
IRI $(\mu \mathrm{U} / \mathrm{mL})$ & $9.8 \pm 3$ & $21.2 \pm 8.3 \dagger$ \\
\hline
\end{tabular}

Abbreviations: $M$, males; $F$, females; FBG, fasting blood glucose, $T G$, serum triglycerides; Lp (a), lipoprotein (a); IRI, fasting immunoreactive insulin.

${ }^{*} P<.001 v$ lean.

$+P<.01 \vee$ lean.

$\mp P<.02 \vee$ lean. total cholesterol (Cholesterol Oxidase), and HDL cholesterol (after precipitation by dextran-magnesium chloride). Apolipoprotein (apo) A1 and B levels were measured by radioimmunodiffusion (Behring, Scoppito, Italy).

Immunoreactive insulin levels were measured by the radioimmunoassay double-antibody method using a commercial kit (Sorin, Saluggia, Italy). Intrassay variation was $7.5 \%$, and interassay variation was $8 \%$; sensitivity for detection of insulin was 2.5 $\mu \mathrm{U} / \mathrm{mL}$.

Lipoprotein(a) levels were assayed by two-site anti-apo(a) immunoradiometric assay with antisera standards and control materials supplied by Pharmacia Diagnostic (Uppsala, Sweden). Crossreactivity with plasminogen and apo $B$ is absent up to a concentration of $8.5 \mathrm{~g} / \mathrm{L}$ for plasminogen and $7 \mathrm{~g} / \mathrm{L}$ for apo $\mathrm{B}$ in this assay. Interassay and intrassay variations were less than $9 \%$ and less than $5 \%$, respectively. ${ }^{17}$

\section{Hemostatic Measurements}

Blood samples for coagulation and fibrinolysis tests were drawn in polypropylene tubes containing one tenth final volume of $3.8 \%$ sodium citrate and kept on crushed ice until centrifugation $\left(4^{\circ} \mathrm{C}\right.$ at $2,500 \times g$ for 15 minutes), and plasma was stored in small aliquots at $-70^{\circ} \mathrm{C}$ until use. A venous occlusion test was also performed in all subjects. A sphygmomanometer cuff was applied to the contralateral arm and inflated midway between systolic and diastolic pressure for 10 minutes. A further blood sample was obtained before deflating the cuff from the occluded arm and separated as previously described. ${ }^{18}$

Tissue plasminogen activator antigen before (tPA1) and after (tPA2) venous occlusion by enzyme-linked immunosorbent assay with a commercially available kit (Innogenetics NY, Antwerp, Belgium), plasminogen activator inhibitor (PAI) activity by chromogenic substrate assay with reagents obtained from Behring (using an automated device, Behring Chromo Time System; Scoppito, Italy), factor VII by a chromogenic substrate assay (Behring Chromo Time System), and fibrinogen and plasminogen by radioimmunodiffusion (Behring) were determined.

Analyses were performed in duplicate following the manufacturer's instructions and, in one series for each participant, within 6 months of sampling.

Assay of all parameters has been well validated in our laboratory. ${ }^{18}$ Normal values were as follows: tPA antigen, $5 \pm 0.5 \mathrm{ng} / \mathrm{mL}$; PAI activity, $3.7 \pm 0.3 \mathrm{U} / \mathrm{mL}$; factor VII activity, $88 \% \pm 5.2 \%$; plasminogen, $10 \pm 1.2 \mathrm{mg} / \mathrm{dL}$; and fibrinogen, $3.4 \pm 0.4 \mathrm{~g} / \mathrm{L}$.

\section{Radionuclide Study}

Systolic and diastolic functions were evaluated by radionuclide angiocardiography using the blood-gated method reported by Bonow et al. ${ }^{19}$ A computerized, large-field scintillation camera (Starcam 400; General Electric, Horsholm, Denmark) with a high-resolution, 1.5-in parallel-hole collimator was used. This method has been validated in our laboratory, in particular in obese subjects. ${ }^{9,10,12,20}$ Left ventricular ejection fraction (LVEF) and peak filling rate ([PFR] = end diastolic volume per second) were measured.

\section{Echocardiographic Study}

Two-dimensional and M-mode echocardiography examination was performed using an ESAOTE Biomedica (Ansaldo, Florence, Italy) computer-aided ultrasound system equipped with 2.5- and 3.5-MHz phased-array transducers and a standard video high system (VHS).

Left ventricular mass (LVM) was calculated according to the 
Devereux method from necropsy-validated studies.21 LVM was also related to body height $(\mathrm{LVM} / \mathrm{H})$ using the recommendation that LVM should be indexed to height instead of body surface area for a more accurate evaluation of left ventricular hypertrophy $(\mathrm{LVH}) .22$

LVH was assumed in the presence of a $\mathbf{L V M} / \mathrm{H}$ greater than 2 standard deviations from the sex-specific mean of a group of 110 normotensive subjects without a family history of hypertension, who provided the normal values for our laboratory. LVH was considered present if $\mathrm{LVM} / \mathrm{H}$ was greater than $120 \mathrm{~g}$ in men and $103 \mathrm{~g}$ in women.

According to these values, none of the obese and lean subjects had LVH.

\section{Statistical Analysis}

Comparisons between lean and obese subjects were performed using an unpaired $t$ test. Linear and multiple regression analyses were used to calculate correlation coefficients between measurements of left ventricular function and tests of coagulation or fibrinolysis. Independent variables in multiple regression analysis were WHR, immunoreactive insulin, factor VII, and PAI, whereas dependent variables were LVEF and PFR. $P$ less than .05 was considered statistically significant. All results are expressed as the mean $\pm \mathrm{SD}$.

\section{RESULTS}

Lean and obese subjects were comparable with regard to gender, age, and height. BMI and WHR were obviously significantly $(P<.001)$ higher in obese than in lean subjects. In addition, fasting blood glucose $(P<.01)$, lipoprotein(a) $(P<.01)$, apo B $(P<.02)$, and serum insulin $(P<.01)$ levels were significantly higher and HDL cholesterol values $(P<.01)$ were significantly lower in young subjects with central obesity than in lean controls. Total cholesterol, serum triglycerides, and apo A1 did not differ significantly between obese and lean groups (Table 1).

\section{Hemostatic Activity and Left Ventricular Function and Structure}

Coagulation and fibrinolytic tests were significantly different between obese and lean subjects. In particular, factor VII, fibrinogen, plasminogen, and PAI activity were significantly $(P<.001)$ higher in obese than in lean subjects. In addition, tPA1 was significantly higher $(P<.02)$ and tPA2 significantly lower $(P<.05)$ in obese than in lean subjects. LVEF $(P<.001)$ and PFR $(P<.02)$ were significantly lower in obese subjects with central fat distribution than in lean controls. In contrast, LVM and LVM/H did not differ between the two groups (Table 2).

\section{Correlations}

WHR correlated directly with fibrinogen $(r=.47$, $P<.05)$ and inversely with tPA2 $(r=-.48, P<.05)$; duration of obesity correlated directly with factor VII activity $(r=.49, P<.05)$ and tPA1 $(r=.48, P<.05)$. In addition, LVEF correlated inversely with tPA1 $(r=-.55$, $P<.001)$, PAI $(r=-.69, P<.001)$, and fibrinogen $(r=-.51, P<.002)$ (Fig 1). PFR correlated inversely with factor VII activity $(r=-.50, P<.05)$.
Table 2. Measurements of Hemostatic Function and Left Ventricular Structure and Function in Lean and Obese Subjects

\begin{tabular}{lcc}
\multicolumn{1}{c}{ Measure } & Lean $(\mathrm{n}=20)$ & Obese $(\mathrm{n}=19)$ \\
\hline Factor VIl activity $(\%)$ & $79 \pm 11$ & $105 \pm 18^{*}$ \\
Fibrinogen $(\mathrm{g} / \mathrm{L})$ & $3.4 \pm 0.7$ & $4.5 \pm 0.8^{*}$ \\
Plasminogen $(\mathrm{mg} / \mathrm{dL})$ & $9.7 \pm 0.8$ & $13.2 \pm 2^{*}$ \\
PAl $(\mathrm{U} / \mathrm{mL})$ & $3.2 \pm 0.3$ & $4.9 \pm 2^{*}$ \\
tPA1 $(\mathrm{ng} / \mathrm{mL})$ & $4.8 \pm 0.7$ & $5.9 \pm 1.6 \dagger$ \\
tPA2 $(\mathrm{ng} / \mathrm{mL})$ & $29 \pm 4$ & $23 \pm 12 \ddagger$ \\
LVM $(\mathrm{g})$ & $135 \pm 35$ & $155 \pm 42$ \\
LVM $/ \mathrm{H}(\mathrm{g} / \mathrm{m})$ & $81 \pm 25$ & $95 \pm 20$ \\
LVEF $(\%)$ & $65.5 \pm 4$ & $56 \pm 10^{*}$ \\
PFR $($ EDV $/ \mathrm{s})$ & $3.55 \pm 0.8$ & $2.9 \pm 0.6 \dagger$ \\
\hline
\end{tabular}

Abbreviation: EDV, end diastolic volume.

${ }^{*} P<.001 v$ lean

$+P<.02 v$ lean.

$\ddagger P<.05 \vee$ lean.

Multiple regression analyses indicated that WHR and PAI were independent predictors of LVEF levels.

\section{DISCUSSION}

This study indicates that obese subjects with central body fat distribution may be characterized by abnormalities in coagulation function and fibrinolytic activity. These included higher levels of factor VII antigen, fibrinogen, plasminogen, PAI activity, and basal tPA, and lower levels of post-venous-occlusion $\mathrm{tPA}$.

Some of these abnormalities were correlated with measurements of left ventricular function such as LVEF and PFR. These data are consistent with the indication that the risk of cardiovascular disease is higher in centrally obese than in lean subjects. ${ }^{1,23,24}$

In fact, elevated fibrinogen and factor VII are reported as risk factors for cardiovascular disease. ${ }^{5,7}$ Moreover, either may be considered an expression of elevated turnover of the coagulation pathway and may be involved in the pathogenesis of ischemic heart disease.,25 In the current study, increased levels of these coagulation factors have been found in subjects with central obesity. Moreover, fibrinogen was directly correlated with WHR and factor VII was directly correlated with duration of obesity, indicating an association among long duration of obesity, body fat distribution of central type, and changes in coagulation function. In these subjects, fibrinogen was also inversely correlated with LVEF, and this may support a relationship between coagulation activity and silent left ventricular dysfunction. These data may be of interest, since general epidemiological studies suggest that high levels of fibrinogen and factor VII may be of casual significance in the development of ischemic heart disease. ${ }^{26}$ Unlike factor VII, fibrinogen is an acute-phase protein and increases in response to a number of stimuli. ${ }^{27}$ However, clinical situations in which fibrinogen levels are high are also characterized by an increase in incidence of venous thrombosis, indicating that this factor has an important role in thrombogenesis. ${ }^{5}$ Fibrinogen is also a major determinant of blood viscosity, which, if 
LVEF (\%)

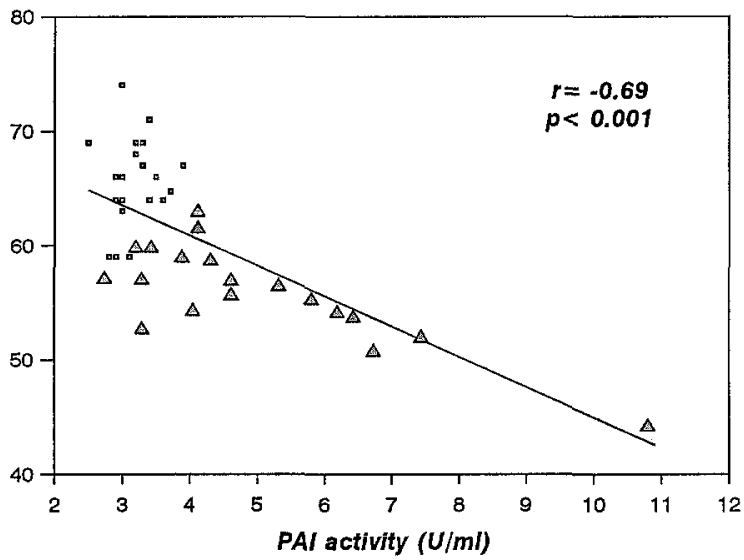

LVEF (\%)

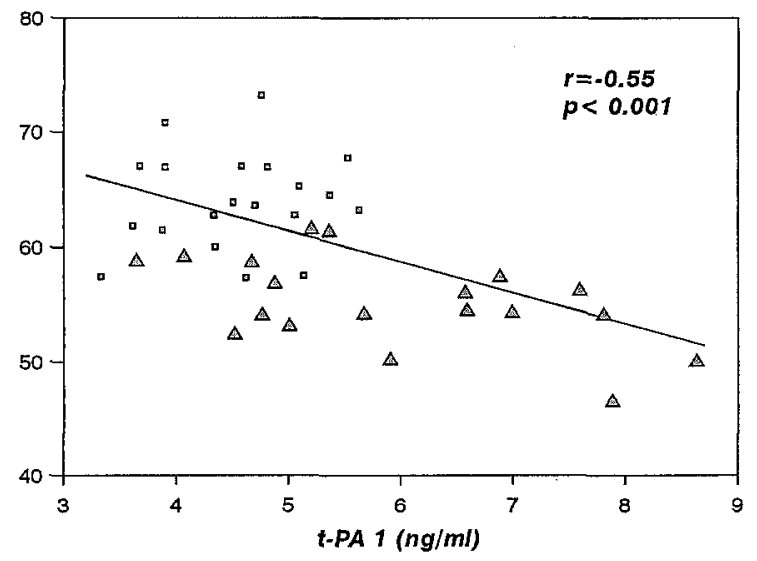

LVEF (\%)

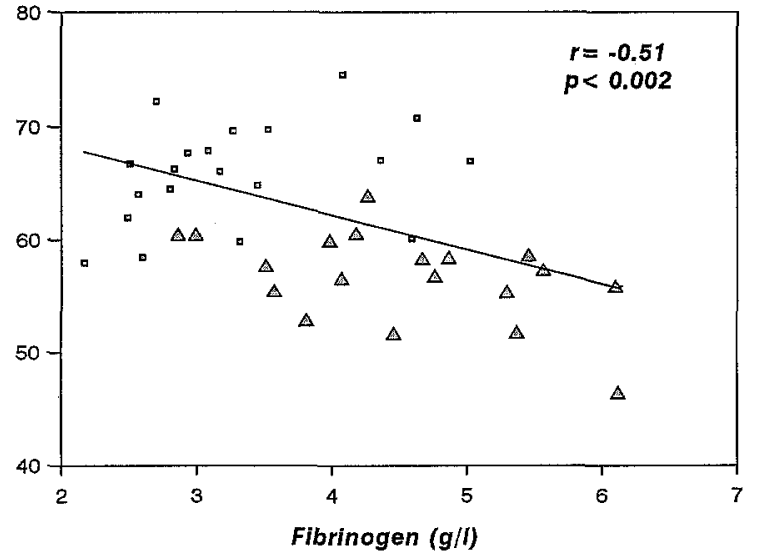

Fig 1. Correlation between LVEF and coagulation and fibrinolytic measurements in lean $(\square)$ and obese $(\triangle)$ subjects.

increased, probably has a casual role in coronary heart disease. ${ }^{28}$

Our data indicate a hypercoagulable state associated with a depressed left ventricular function in subjects with central obesity.

It has been recently reported that elevated PAI levels are associated with an increased recurrence of myocardial infarction..$^{29,30}$ In addition, increased PAI levels may be detectable in patients with coronary spastic angina. ${ }^{31}$

The relationships between central obesity and fibrinolytic activity have been well investigated by Landin et al. ${ }^{8}$ They reported that a high WHR in obesity was associated with an impaired fibrinolytic activity. In addition, Vague et $\mathrm{a}^{32}$ have provided evidence that hyperinsulinemia may be an important reason for the impaired fibrinolytic activity.

In our study, the role of hyperinsulinemia in promoting depressed fibrinolytic activity remains uncertain. In fact, despite insulin levels that were higher in obese than in lean subjects, no evidence indicated an independent effect of fasting insulin on the change in fibrinolytic activity.

In the present study, increased PAI and a depressed fibrinolytic activity have been demonstrated in subjects with central obesity. WHR and PAI activity remained the best predictors of LVEF in multiple regression analysis. This indication is further supported by results of the European Concerted Action on Thrombosis and Disabilities (ECAT) study. ${ }^{6}$ In this study, a decreased pump function associated with increased PAI and decreased fibrinolytic activity both before and after stimulation by venous occlusion has been reported. An explanation for the mechanisms responsible for the abnormalities in hemostatic function detectable in our obese subjects remains unclear. They might indicate that it is possible to detect early suitable markers of atherosclerosis in subjects with central obesity. This is also supported by lower HDL levels and higher apo B and lipoprotein(a) values in obese than in lean comparable subjects.

In conclusion, obese subjects with central body fat distribution showed an atherogenic profile characterized by metabolic and hemostatic abnormalities associated with silent left ventricular dysfunction. Further prospective data must be provided to demonstrate if cardiac events occur more frequently in obese than in lean subjects.

\section{REFERENCES}

1. Licata G, Corrao S, Parrinello G, et al: Obesity and cardiovascular diseases. Ann Ital Med Int 9:29-32, 1994

2. Must A, Jacques PF, Dallal GE, et al: Long-term morbidity and mortality of overweight adolescents. A follow-up of the Harvard Growth Study of 1922 to 1935 . N Engl J Med 327:13501355, 1992

3. Mueller WH: The changes with age of the anatomical distribution of fat. Soc Sci Med 16:191-196, 1982

4. Deutsch MI, Mueller WH, Malina RM: Androgyny in fat patterning is associated with obesity in adolescents and young adults. Ann Hum Biol 12:275-286, 1985

5. Meade TW, Brozovic M, Chakrabarti RR, et al: Haemostatic function and ischaemic heart disease: Principal results of the Northwick Park Heart Study. Lancet 2:533-537, 1986

6. ECAT Angina Pectoris Study Group: Baseline associations of haemostatic factors with extent of coronary arteriosclerosis and other coronary risk factors in 3000 patients with angina pectoris undergoing coronary angiography. Eur Heart J 14:8-17, 1993

7. Balleisen L, Bailey J, Epping PH, et al: Epidemiological study on factor VII, factor VIII and fibrinogen in an industrial population. I. Baseline data on the relation to age, gender, body-weight, 
smoking, alcohol, pill-using, and menopause. Thromb Haemost 54:475-479, 1985

8. Landin K, Stigendal L, Eriksson E, et al: Abdominal obesity is associated with an impaired fibrinolytic activity and elevated plasminogen activator inhibitor-1. Metabolism 39:1044-1048, 1990

9. Licata G, Scaglione R, Barbagallo M, et al: Effect of obesity on left ventricular function studied by radionuclide angiocardiography. Int J Obes 15:295-302, 1991

10. Licata G, Scaglione R, Paterna S, et al: Left ventricular function response to exercise in normotensive obese subjects: Influence of degree and duration of obesity. Int J Cardiol 37:223230, 1992

11. Merlino G, Scaglione R, Paterna S, et al: Lymphocyte beta adrenergic receptors in young subjects with peripheral or central obesity: Relationship with central haemodynamic and left ventricular function. Eur Heart J 15:786-792, 1994

12. Scaglione R, Dichiara MA, Indovina A, et al: Left ventricular diastolic and systolic function in normotensive obese subjects: Influence of degree and duration of obesity. Eur Heart J 13:738742, 1992

13. Beard CM, Orencia A, Kottke T, et al: Body mass index and the initial manifestation of coronary heart disease in women aged 40-59 years. Int J Epidemiol 21:656-664, 1992

14. Licata G, Scaglione R, Giammaresi C, et al: No evidence of platelet activation in obesity. Thromb Haemost 70:544, 1993 (letter)

15. Avellone G, Di Garbo V, Cordova R, et al: Coagulation, fibrinolysis and haemorrheology in premenopausal obese women with different body fat distribution. Thromb Res (in press)

16. Crepaldi G, Belfiore S, Bosello O, et al: Special Report: Italian Consensus Conference-Overweight, obesity and health. Int J Obes 15:781-790, 1991

17. Scaglione R, Corrao S, Dichiara MA, et al: Plasma lipoprotein(a) in young obese subjects: Relationships with markers of cardiovascular risk. J Cardiovasc Risk (in press)

18. Avellone G, Di Garbo V, Cordova R, et al: Fibrinolysis in hypertriglyceridaemic subjects in response to venous occlusion. Blood Coag Fibrinol 4:429-433, 1993

19. Bonow RO, Bacarach SL, Green MV, et al: Impaired left ventricular diastolic filling in patients with coronary artery diseases: Assessment with radionuclide angiography. Circulation $64: 315-323,1981$
20. Licata G, Scaglione R, Parrinello G, et al: Rapid left ventricular filling in untreated hypertensive subjects with or without left ventricular hypertrophy. Chest 102:1507-1511, 1992

21. Devereux RB, Alonzo DR, Lutas EM, et al: Echocardiographic assessment of left ventricular hypertrophy: Comparison to necropsy findings. Am J Cardiol 57:450-458, 1986

22. Levy D, Anderson KM, Savage DD, et al: Echocardiographically detected left ventricular hypertrophy: Prevalence and risk factors: The Framingham Heart Study. Ann Intern Med 108:7-13, 1988

23. Manson JE, Colditz GA, Stampfer MJ, et al: A prospective study of obesity and risk of coronary heart disease in women. $\mathrm{N}$ Engl J Med 322:882-889, 1990

24. Larrson B, Svardsudd K, Welin L, et al: Abdominal a dipose tissue distribution, obesity and risk of cardiovascular disease and death: 13-year follow-up of participants in the study of men born in 1913. Br Med J 288:1401-1404, 1984

25. Wilhelmsen L, Svardsudd K, Korsan-Bengtsen K, et al: Fibrinogen as risk factor for stroke and myocardial infarction. $N$ Engl J Med 311:501-505, 1984

26. Meade TW: Clotting factors and ischaemic heart disease: The epidemiological evidence, in Meade TW (ed): Anticoagulants and Myocardial Infarction. Chichester, UK, Wiley, 1984, pp 91-112

27. Brozovic M: Physiological mechanisms in coagulation and fibrinolysis. Br Med Bull 33:231-238, 1977

28. Lowe GDO, Drummond MM, Lorimer AR, et al: Relation between extent of coronary heart disease and blood viscosity. $\mathrm{Br}$ Med J 1:673-674, 1980

29. Hamsten A, Walldius G, Szamosi A, et al: Plasminogen activator inhibitor in plasma, a risk factor for recurrent myocardial infarction. Lancet 1:3-8, 1987

30. Nilsson T, Johnson O: The extrinsic fibrinolytic system in survivors of myocardial infarction. Thromb Res 48:621-640, 1987

31. Masuda $T$, Yasue $\mathrm{H}$, Ogawa $\mathrm{H}$, et al: Plasma plasminogen activator inhibitor activity and tissue plasminogen activator levels in patients with unstable angina and those with coronary spastic angina. Am Heart J 124:314-319, 1992

32. Vague P, Juhan-Vague I, Ailhaud MF, et al: Correlation between blood fibrinolytic activity, plasminogen activator inhibitor level, plasma insulin level and relative body weight in normal and obese subjects. Metabolism 35:250-263, 1986 